\title{
Multinational outbreak of travel-related Salmonella Chester infections in Europe, summers 2014 and 2015
}

L Fonteneau ${ }^{12}$, N Jourdan Da Silva ${ }^{1}$, L Fabre ${ }^{3}$, P Ashton ${ }^{4}$, M Torpdahl 5 , L Müller ${ }^{5}$, B Bouchrif 6 , A El Boulani 7 , E Valkanou ${ }^{8}$, W Mattheus $^{9}$, I Friesema ${ }^{10}$, S Herrera Leon ${ }^{11}$, C Varela Martínez ${ }^{12}$, J Mossong ${ }^{13}$, E Severi ${ }^{14}$, K Grant ${ }^{4}$, F Weill ${ }^{3}$, CM Gossner ${ }^{14}$ ${ }^{15}$, S Bertrand 9 , T Dallman ${ }^{4}$, S Le Hello ${ }^{3}$

1. Santé publique France, the French national public health agency, Saint-Maurice, France

2. European Programme for Intervention Epidemiology Training (EPIET), European Centre for Disease Prevention and Control (ECDC), Stockholm, Sweden

3. Institut Pasteur, French National Reference Center for E. coli, Shigella and Salmonella, Paris, France

4. Public Health England, Gastrointestinal Bacterial Reference Unit, London, England

5. Statens Serum institut (SSI), Denmark

6. Institut Pasteur du Maroc, Sécurité alimentaire et environnement, Casablanca, Morocco

7. University Ibn Zohr, LBVRN, Agadir, Morocco

8. NRL Salmonella \& AMR, Veterinary Laboratory of Chalkida, Greece

9. NRL Salmonella, Institute of Public Health, Belgium

10. Netherlands National Institute for Public Health and the Environment (RIVM), the Netherlands

11. National Center for Microbiology. Instituto de Salud Carlos III, Spain.

12. Instituto de Salud Carlos III, CIBER Epidemiología y Salud Pública (CIBERESP), Spain

13. Laboratoire National de Santé, Luxembourg

14. European Centre for Disease Prevention and Control, Stockholm, Sweden

15. School of Public Health and Primary Care (CAPHRI), Maastricht University Medical Center (MUMC+), Maastricht, the Netherlands

Correspondence: Simon Le Hello (slehello@pasteur.fr) and Nathalie Jourdan-Da Silva (Nathalie.JOURDAN-DASILVA@ santepubliquefrance.fr)

Citation style for this article:

Fonteneau L, Jourdan Da Silva N, Fabre L, Ashton P, Torpdahl M, Müller L, Bouchrif B, El Boulani A, Valkanou E, Mattheus W, Friesema I, Herrera Leon S, Varela Martínez C, Mossong J, Severi E, Grant K, Weill F, Gossner CM, Bertrand S, Dallman T, Le Hello S. Multinational outbreak of travel-related Salmonella Chester infections in Europe, summers 2014 and 2015. Euro Surveill. 2017;22(7):pii=30463. DOI: http://dx.doi.org/10.2807/1560-7917. ES.2017.22.7.3046

Between 2014 and 2015, the European Centre for Disease Prevention and Control was informed of an increase in numbers of Salmonellaenterica serotype Chester cases with travel to Morocco occurring in six European countries. Epidemiological and microbiological investigations were conducted. In addition to gathering information on the characteristics of cases from the different countries in 2014, the epidemiological investigation comprised a matched case-case study involving French patients with salmonellosis who travelled to Morocco that year. A univariate conditional logistic regression was performed to quantify associations. The microbiological study included a whole genome sequencing (WGS) analysis of clinical and non-human isolates of $S$. Chester of varied place and year of isolation. A total of 162 cases, mostly from France, followed by Belgium, the Netherlands, Spain, Denmark and Sweden were reported, including 86 (53\%) women. The median age per country ranged from 3 to 38 years. Cases of $S$. Chester were more likely to have eaten in a restaurant and visited the coast of Morocco. The results of WGS showed five multilocus sequence types (ST), with 96 of 153 isolates analysed clustering into a tight group that corresponded to a novel ST, ST1954. Of these 96 isolates, 46 (48\%) were derived from food or patients returning from Morocco and carried two types of plasmids containing either $q n r S_{1}$ or $q n r B 19$ genes. This European-wide outbreak associated with travel to Morocco was likely a multisource outbreak with several food vehicles contaminated by multidrug-resistant $S$. Chester strains.

\section{Introduction}

Non-typhoidal Salmonella infections are the most common cause of reported food-borne outbreaks in the European Union (EU) [1,2]. These infections mostly cause mild disease (gastroenteritis), however lifethreatening infections (e.g. bacteraemia) may occur, particularly in cases involving patients at the extremes of age or who are immunocompromised. Due to the large animal reservoir, including farm animals, pets and wild animals, Salmonella is mainly transmitted by consumption of contaminated food and to a lesser extent by contaminated environments, contact with animals, or person-to-person [3]. The mean incubation period is between 1 and 3 days. More than 2,500 serotypes of the genus Salmonella have been described so far [4].

Of these, serotype Chester is not commonly identified through human surveillance. Between 2009 and 2013, EU and European Economic Area (EU/EEA) countries 


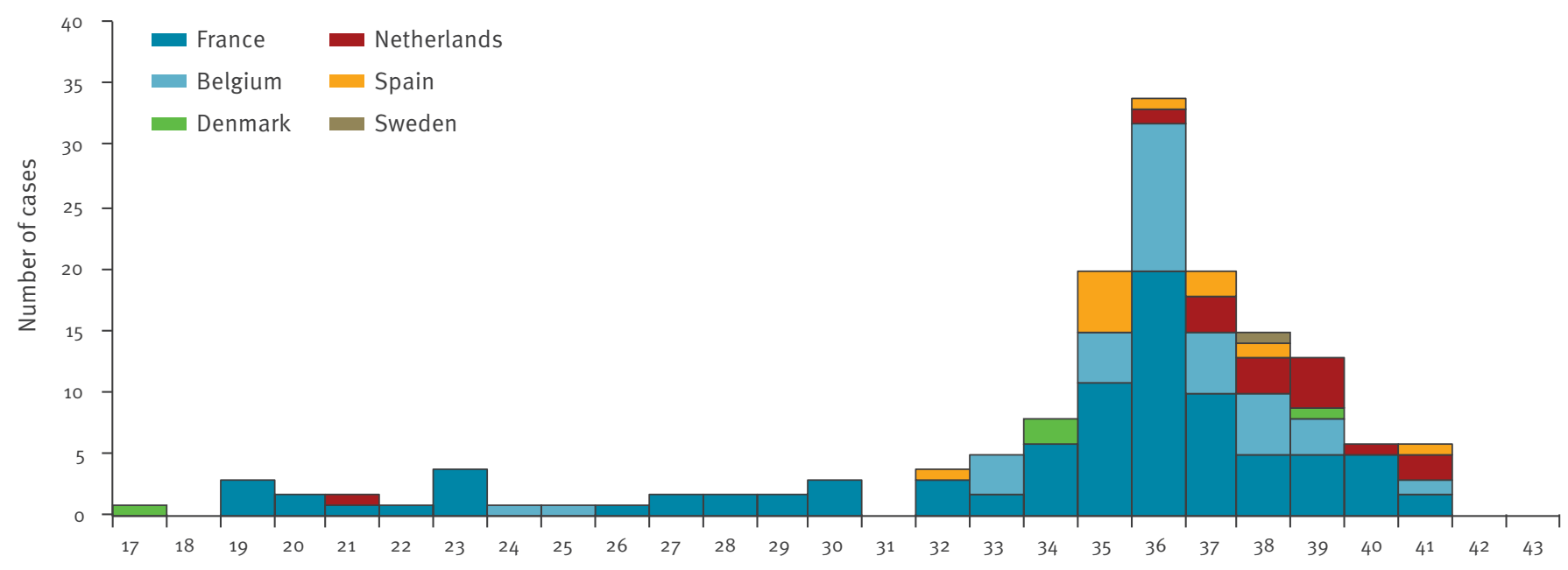

Week of strain isolation (2014)

reported through The European Surveillance System (TESSy) a mean of $91 \mathrm{~S}$. Chester cases per year, which accounts for only $0.1 \%$ of all annual salmonellosis cases notified in the EU/EEA [5]. Outbreaks associated with $S$. Chester have been reported: in Australia, associated with sea turtle meat in 1998 and with tap water in 2005; in the United States, associated with cantaloupe in 1990 and with frozen meals (cheesy chicken and rice) in 2010; in Japan associated with cuttlefish chips in 1999 and in Canada, associated with headcheese in 2010 [6-11]. S. Chester was also the second most common serotype in poultry, in 2010, in Burkina Faso [12]. From 2005 to 2015, according to the Rapid Alert System for Food and Feed (RASFF, http:// ec.europa.eu/food/safety/rasff/index_en.htm) database, a EU tool to share information when cross-border risks to public health are detected in the food chain, $S$. Chester was found in kangaroo meat (twice in 2007 and 2011 respectively), peppermint (once in 2005), dog chew (once in 2005) and fishmeal (six times in 2014) [13].

In France, the human Salmonella surveillance system is based on a voluntary network of laboratories that send or report their Salmonella isolates to the French National Reference Center for Escherichia coli, Shigella and Salmonella (NRC) $[14,15]$. Travel information is collected from laboratory surveillance forms (completed for ca $30 \%$ of the patients in 2014). In addition, foodborne outbreaks of salmonellosis (at least two cases clustered in time and place) are subject to mandatory notification to the French Institute for Public Health Surveillance (Santé publique France; SpF).

In September 2014, the French NRC notified SpF of an increase in numbers of $S$. Chester isolates, with 31 isolates received between August and September 2014, slightly more than twice the number observed for the same period in $2013(n=14)$. Most cases had travelled to Morocco within two weeks prior to their symptom onset. During the same period, Belgium had initiated a similar notification to the European Epidemic Intelligence Information System (EPIS) of the European Centre for Disease Prevention and Control (ECDC) with 18 S. Chester cases. The Netherlands, Spain and Denmark reported clusters of, respectively eight, six, and four cases, and Sweden reported one case [1]. In September 2014, a European investigation was launched in order to identify the vehicle(s)/source(s) of infection and implement control measures. France, the country with the highest number of cases, coordinated this investigation with the support of the ECDC.

In this article, we describe the epidemiological and microbiological investigations of the outbreak and report and discuss their outcome.

\section{Methods}

We carried out both epidemiological and microbiological investigations. The epidemiological investigation only included cases with symptom onset in 2014 while the microbiological investigation considered cases with onset occurring over a larger time frame as further described.

\section{Epidemiological investigation}

We defined a case as a symptomatic resident of the EU/ EEA with laboratory-confirmed $S$. Chester infection and with symptom onset (or date of strain isolation in case of unavailable onset date) between week 17 (April) and week 41 (October) of 2014 .

We described cases in terms of age, sex and travel history to Morocco. 


\section{FIGURE 2}

Phylogenetic tree of Salmonella enterica serotype Chester, European Union, 1937-2015 ( $\mathrm{n}=153$ isolates)

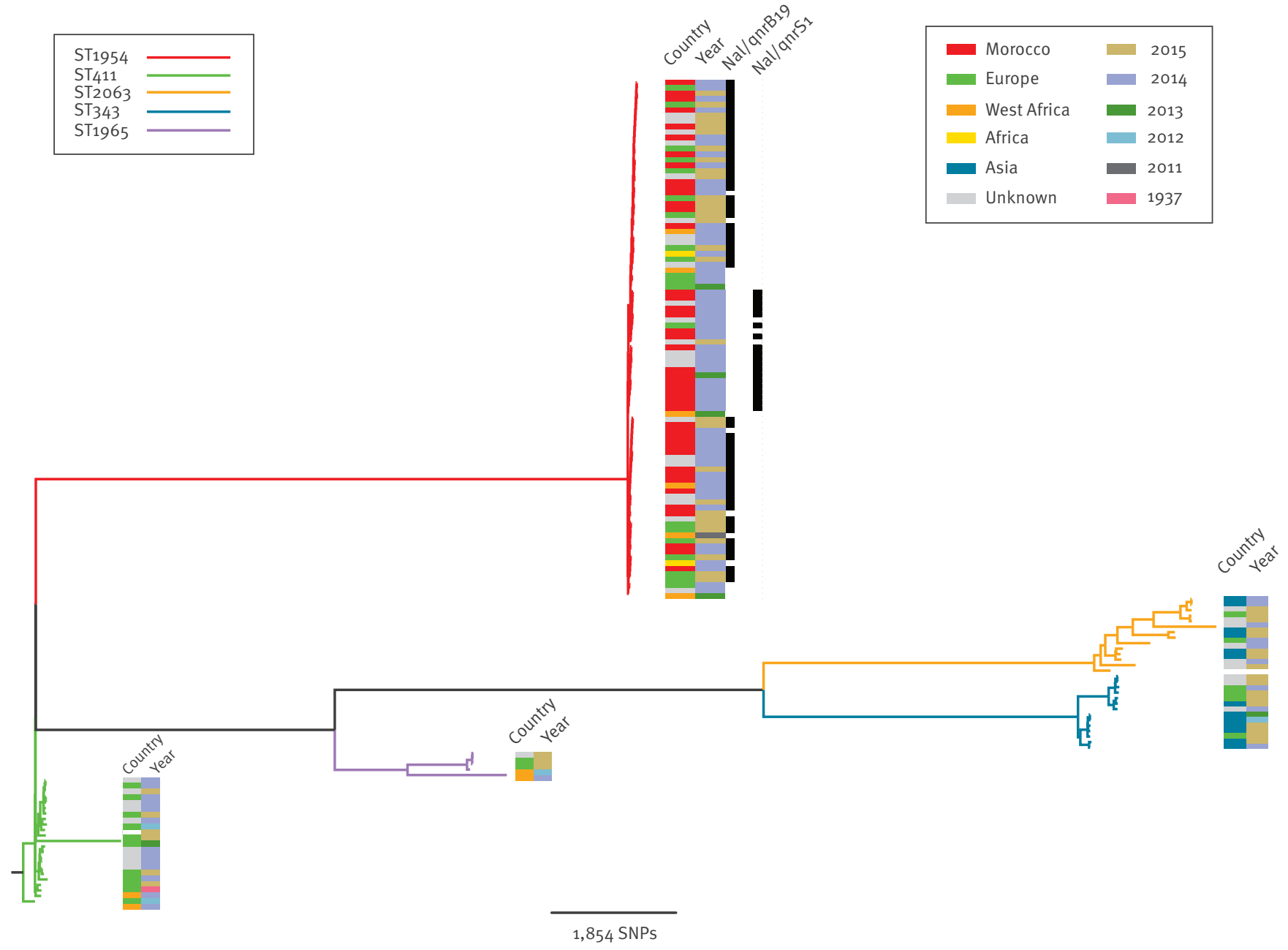

Nal: nalidixic acid; SNP: single nucleotide polymorphism; ST: sequence type.

Maximum-likelihood phylogenetic tree based on the analysis of 11,879 chromosomal SNPs from the 153 short read sequences of Salmonella Chester using harvest v1.0.1 f parsnp function against the $17 \mathrm{~K}$ reference strain and rooted on the 201009678 genome. Branches distributing in a cluster corresponding to a given ST are assigned a specific colour and different colours are respectively used for ST1954, ST411, $\mathrm{ST}_{2063}$, ST343 and ST1965. The geographical area of acquisition/collection of the strain and the year of isolation are shown on the right of each branch together with information as to whether the strain has a Col/qnrB19 plasmid or an IncN/qnrS1 plasmid (whereby presence of either plasmid is indicated by a black box). The remaining quinolone-susceptible isolates are indicated by the absence of a black box (in particular for all the non-ST1954 isolates).

The SNP difference among the 96 isolates of the ST1954 cluster ranged between o and 214 SNPS; the ST1954 cluster itself was at a distance of 8,453 SNPs from the reference strain.

In France, we interviewed the most recently infected cases (with isolates obtained from week 33 of 2014) using a trawling questionnaire. This gathered information on demographics, clinical details, travel within the seven previous days with a focus on Morocco, contact with symptomatic persons, attended events, visited places and a detailed food history for the week before symptom onset. If the case was a child aged less than 15 years, we interviewed one of his/her parents.

The Dutch and Belgian Institutes used the same questionnaire to interview their cases. The Danish and
Spanish cases were interviewed using a different questionnaire focusing on travel destination and whereabouts during the travel. The Swedish case was not interviewed on exposures.

In France, SpF carried out a matched case-case study to test the hypotheses raised by the exploratory investigation. We interviewed cases, with symptom onset between week 31 and week 40, who were not included in the exploratory investigation. We selected controls, among non-typhoidal Salmonella cases, who were diagnosed with an infection by other serotypes than 


\section{FIGURE 3}

Maximum Likelihood phylogeny of the Salmonella Chester ST1954 strains, European Union (n=96 strains)

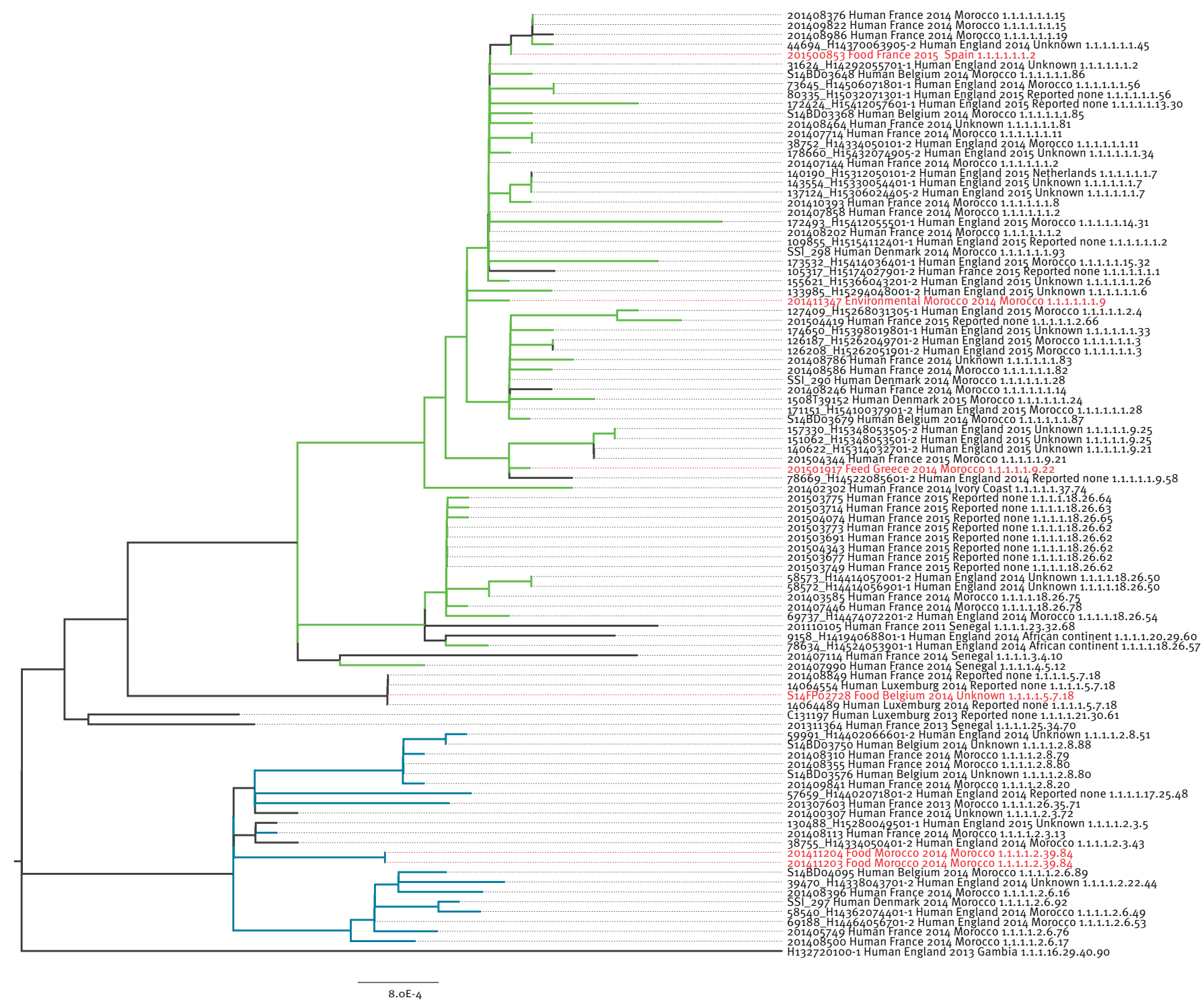

ST1954 strains were mapped to the Spades v2.5.1 de novo assembly of isolate 60056_H14424061601-2 using BWA-MEM. The taxa are labelled with the strain number, isolate source, country of origin, year of isolation, travel information, and single nucleotide polymorphism (SNP) address. Hierarchical single linkage clustering was performed on the pairwise SNP difference between all isolates at various distance thresholds. The SNP address is a seven number indicating the range of SNPs as follow: $\Delta 250, \Delta 100, \Delta 50, \Delta 25, \Delta 10, \Delta 5, \Delta 0$. In green, the QnrB19-producing isolates; in blue, the QnrS1-producing isolates; in black the susceptible-quinolone isolates and in red, the non-human isolates.

Chester, who reported travel history to Morocco in the week before symptoms and whose symptoms started between week 27 and week 40 of 2014 . We selected two controls for each case. After excluding cases who did not travel to Morocco before being symptomatic, we performed a crude analysis and three matched analyses. We separately matched cases with controls according to their age group $(\langle 1,1-5,6-15,16-40\rangle 40$, years of age), according to the week of their symptom onset (plus or minus two weeks) and according to both their age group and week of symptom onset.
We performed a univariate conditional logistic regression to quantify associations. We calculated matched odds ratios (mORs) and their 95\% confidence interval (CI). We used Stata v12.1 (Stata Corporation, Texas, US) for analysis.

\section{Microbiological investigations conducted at the European Union level}

A microbiological investigation was conducted at the EU level, whereby countries were also asked whether they could participate in a whole genome sequencing (WGS) study. Five EU countries consisting of England and Wales (which conduct WGS routinely), France, 
Characteristics of Salmonella Chester cases, European Union, $2014(\mathrm{n}=162)$

\begin{tabular}{|l|c|c|c|c|c|c|c|}
\hline Characteristics & $\begin{array}{c}\text { France } \\
(\mathrm{n}=90)\end{array}$ & $\begin{array}{c}\text { Belgium } \\
(\mathrm{n}=35)\end{array}$ & $\begin{array}{c}\text { Netherlands } \\
(\mathrm{n}=15)\end{array}$ & $\begin{array}{c}\text { Spain } \\
(\mathrm{n}=11)\end{array}$ & $\begin{array}{c}\text { Denmark } \\
(\mathrm{n}=10)\end{array}$ & $\begin{array}{c}\text { Sweden } \\
(\mathrm{n}=1)\end{array}$ & $\begin{array}{c}\text { All } \\
(\mathrm{n}=162)\end{array}$ \\
\hline Proportion of women $\mathrm{n}(\%)$ & $51(57)$ & $15(43)$ & $10(67)$ & $6(55)$ & $4(40)$ & 0 & $86(53)$ \\
\hline Median age (years) & 3 & 14.5 & 5 & 6 & 38 & NA & NA \\
\hline $\begin{array}{l}\text { Number of cases with known travel } \\
\text { information }\end{array}$ & 20 & 8 & 12 & 5 & 9 & 1 & 55 \\
\hline $\begin{array}{l}\text { Number of cases that travelled to } \\
\text { Morocco }\end{array}$ & 17 & 8 & 10 & 5 & 4 & 1 & 45 \\
\hline
\end{tabular}

NA: not applicable.

Denmark, Belgium and Luxemburg, took part, making, overall, a total of $153 \mathrm{~S}$. Chester isolates available for the investigation. One hundred and forty seven human isolates were selected so as to reflect a significant diversity in terms of year of isolation, geographical area of acquisition and potential link with the present multinational outbreak. Six non-human isolates from 2014 and 2015 were also added. Of the 147 human isolates, 82 were isolated in England and Wales between 2012 and 2015, 45 in France between 2011 and 2015 (including 26 isolates obtained during the epidemiological investigation), nine in Denmark in 2014 and 2015 (including 6 from the epidemiological investigation), six in Belgium in 2014 (all were from the epidemiological investigation) and three in Luxemburg between 2013 and 2014. The two remaining isolates were the reference strains (17K and ATCC 11997). 17K represents the historical reference strain first isolated from humans during a food poisoning outbreak in the hospital of Chester, United Kingdom (UK) in 1937 [16] and the ATCC 11997 is a reference strain from the Centers for Disease Control and Prevention of the United States (US CDC) [17]. Among these 145 patients, 71 (49\%) reported international travel two weeks before illness onset (mainly in Morocco, $n=42$ and West African countries, $n=10$ ), 34 reported no travel and for the 40 remaining patients, this information was unknown. Of the six non-human isolates, three were collected from food (two from chicken sausages in Casablanca, Morocco and one from poultry in Belgium), one from decanted water in a treatment plant in Agadir, Morocco, one from turkey meat isolated in France but imported from Spain and the remaining isolate was isolated from fishmeal. Contrary to the other isolates obtained from random controls, this latter strain was sent upon request by the Greek authorities to the NRC in 2015 after a notification through RASFF about border rejection of fishmeal from Morocco in October 2014.

For all isolates sent to the French NRC (including the six human isolates from Belgium, the 45 human isolates from France and the six non-human isolates), the serotype was confirmed by agglutination tests with antisera (Bio-Rad, Marnes-la-Coquette, France) according to the White-Kauffmann-Le Minor scheme [4]. For the
82 English and Welsh, the nine Danish and the three Luxemburgish isolates, the serotype was determined from genome sequences, which were shared.

A total of 105 S. Chester isolates were selected for antimicrobial susceptibility testing (AST). These consisted of 35 of the 82 isolates from England and Wales, and all human isolates from France $(n=45)$, Denmark $(n=9)$, Belgium $(n=6)$, Luxemburg $(n=3)$ as well as the six hon-human isolates and the $17 \mathrm{~K}$ reference strain. AST was carried out by the disk diffusion method, with a panel of 32 antimicrobial drugs (Bio-Rad) as previously described [18]. The minimal inhibitory concentration (MIC) of nalidixic acid, ciprofloxacin, azithromycin and colistin were determined by using Etests (BioMérieux, Marcy l'Etoile, France) and interpreted according to the European Committee on Antimicrobial Susceptibility Testing (EUCAST) clinical guidelines [19].

PulseNet standard pulsed-field gel electrophoresis (PFGE) of Xbal-digested chromosomal DNA was performed on a subset of 36 isolates. PFGE profiles were compared using Bionumerics software, v6.6 (Applied Maths, Sint Martens Latem, Belgium) and by the molecular typing clusters detection tools of ECDC.

For English and Welsh, French, Danish, Belgian and Luxemburgish $S$. Chester strains, genomic DNA was extracted and purified using different kits (Wizard of Promega or QiaAmp of Qiagen) and DNA samples were processed according to Illumina systems (MiSeq, NextSeq or HiSeq) generating 150 bp pairedend reads. Sequences were transferred to NRC for compiled analysis. Reads were trimmed and filtered using AlienTrimmer [20] with a quality Phred score threshold of 28 on a minimum length of $30 \mathrm{nt}$. De novo assembly was performed with SPAdes assembler version v2.5.1 [21]. Assembled sequences were analysed using web-tools available from the Center for Genomic Epidemiology (CGE) website (http://www.genomicepidemiology.org/) to obtain the multilocus sequence typing (MLST) type, to detect resistance genes (ResFinder) and to detect and type plasmids (PlasmidFinder and pMLST). New MLST types were confirmed by Sanger 
TABLE 2

Assessing associations between exposures and cases of Salmonella Chester infection by univariate conditional logistic regression, France, 2014 ( $n=14$ cases)

\begin{tabular}{|c|c|c|c|c|c|c|}
\hline \multirow[t]{2}{*}{ Exposure } & \multicolumn{2}{|c|}{$\begin{array}{l}\text { Cases } \\
(\mathrm{N}=14)\end{array}$} & \multicolumn{2}{|c|}{$\begin{array}{l}\text { Control-cases } \\
\quad(\mathrm{N}=26)\end{array}$} & \multirow[t]{2}{*}{ Matched $\mathrm{OR}^{\mathrm{b}}$} & \multirow[t]{2}{*}{$95 \% \mathrm{Cl}$} \\
\hline & $n$ & $\%^{a}$ & $n$ & $\%^{\mathrm{a}}$ & & \\
\hline \multicolumn{7}{|l|}{ Meat } \\
\hline Beef & 12 & 92 & 20 & 80 & 2.7 & $0.26-28$ \\
\hline Lamb/sheep meat & 5 & 42 & 14 & 54 & 0.5 & $0.12-2.2$ \\
\hline Chicken & 11 & 79 & 22 & 85 & 0.6 & $0.12-3.2$ \\
\hline Chicken sausage & 3 & 21 & 4 & 16 & 1.3 & $0.22-8.0$ \\
\hline Turkey ham & 1 & 7 & 8 & 31 & 0.2 & $0.02-1.7$ \\
\hline Cachir & 2 & 14 & 6 & 23 & 0.6 & $0.10-3.5$ \\
\hline Poultry meat sandwich & 2 & 25 & 5 & 24 & 1 & $0.05-19$ \\
\hline \multicolumn{7}{|l|}{ Milk and eggs products } \\
\hline Pasteurised milk & 6 & 55 & 16 & 76 & 0.2 & $0.02-1.7$ \\
\hline Yogurt & 8 & 57 & 19 & 76 & 0.4 & $0.06-2.2$ \\
\hline Spreadable cheese & 7 & 54 & 16 & 64 & 0.7 & $0.08-5.3$ \\
\hline Scrambled eggs & 6 & 49 & 6 & 29 & 3 & $0.54-16$ \\
\hline \multicolumn{7}{|l|}{ Vegetables and fruits } \\
\hline Tomato & 11 & 78 & 18 & 69 & 1.4 & $0.33-6.0$ \\
\hline Cucumber & 9 & 69 & 16 & 64 & 1.2 & $0.28-5.3$ \\
\hline Grapes & 10 & 71 & 18 & 72 & 1 & $0.27-0.7$ \\
\hline Melon & 9 & 64 & 20 & 77 & 0.6 & $0.12-2.8$ \\
\hline Water melon & 10 & 71 & 21 & 81 & 0.5 & $0.08-2.7$ \\
\hline Olives & 7 & 50 & 15 & 60 & 0.7 & $0.16-3.1$ \\
\hline \multicolumn{7}{|l|}{ See food and fish } \\
\hline Sardine & 6 & 43 & 8 & 31 & 1.5 & $0.44-5.0$ \\
\hline Shrimp & 7 & 50 & 4 & 15 & 5.6 & $1.1-28$ \\
\hline Squid & 6 & 43 & 4 & 15 & 3.3 & $0.81-14$ \\
\hline \multicolumn{7}{|l|}{ Sweets } \\
\hline Ice cream & 10 & 71 & 15 & 60 & 1.6 & $0.36-7.2$ \\
\hline Popcorn & 4 & 31 & 8 & 32 & 0.9 & $0.21-0.9$ \\
\hline \multicolumn{7}{|l|}{ Eating place } \\
\hline Fast food $\mathrm{X}$ attendance & 4 & 29 & 5 & 19 & 1.9 & $0.39-8.9$ \\
\hline Restaurant attendance & 14 & 100 & 18 & 69 & 6.2 & $1.1-295^{c}$ \\
\hline Shrimp consumption in restaurant & 6 & 43 & 1 & 4 & 11.1 & $1.3-92.5^{c}$ \\
\hline \multicolumn{7}{|l|}{ Place of residence } \\
\hline Residing on the coast & 11 & 92 & 9 & 41 & 9.3 & $1.1-78$ \\
\hline
\end{tabular}

$\mathrm{Cl}$ : confidence interval; OR: odds ratio.

${ }^{a}$ Percentages are based on the number of cases or control-cases who answered the questionnaire about a given exposure. These numbers can be less than the totals provided in respective column headers.

${ }^{b}$ OR matched on age categories and week of symptom onset.

${ }^{\mathrm{C}}$ Crude odds ratio.

sequencing according to the MLST database website (http://mlst.warwick.ac.uk/mlst/).

As there is no complete $S$. Chester reference genome in public databases, core-genome multi-alignment of assembled genomes was done using harvest v1.0.1 $f$ parsnp function [22] against the $17 \mathrm{~K}$ reference strain or the ATCC 11997 S. Chester assembly $[16,17]$. The software uses FastTree2 to infer an approximately maximumlikelihood phylogenetic tree based on the analysis of 11,879 chromosomal single-nt polymorphisms (SNPs) from the 153 short read sequences of S. Chester [23]. The final tree was visualised in FigTree version 1.4 .2 (http://tree.bio.ed.ac.uk/software/figtree/).

A sequence type (ST)1954 specific S. Chester phylogeny was constructed. ST1954 short-read sequences were mapped to the SPAdes V2.5.1 [21] de novo assembly of isolate 60056_H14424061601-2 using BWA-MEM [24]. SNPs were identified using GATK2 [25] in unified genotyper mode. Genome positions that had a high quality SNP (>90\% consensus, minimum depth $10 x, G Q \geq 30$ ) in 
at least one isolate were extracted. Pseudosequences of polymorphic positions were used to create maximum likelihood trees using RAxML [26] and pairwise SNP distances between each pseudosequence calculated. Hierarchical single linkage clustering was performed on the pairwise SNP difference between all isolates at various distance thresholds $(\Delta 250, \Delta 100$, $\left.\Delta_{50}, \Delta 25, \Delta 10, \Delta 5, \Delta 0\right)$. The result of the clustering is a SNP address that can be used to describe the population structure based on clonal groups [27].

FASTQ sequences were deposited in the National Center for Biotechnology Information (NCBI) Short Read Archive under the BioProject PRJNA248792.

\section{Results}

\section{Epidemiological investigations}

Between week 17 and 41 of 2014, six EU countries (France, Belgium, the Netherlands, Spain, Denmark and Sweden) reported 162 cases through EPIS. The number of reported cases peaked on the first week of September (week 36, 2014) (Figure 1).

Of the 162 EU cases, about half of the cases ( $86 ; 53 \%)$ were women and the median age ranged from 3 to 38 years according to the country of notification. We obtained the travel history for 55 cases and 45 (82\%) had recently travelled to Morocco (Table 1 ).

In France, 16 cases were interviewed (8 females, 8 males) with a median age of 2 years (range: $1-32$ years). Four cases aged between 1 and 3 years had been hospitalised (median length of hospitalisation: 5.5 days). Fifteen of the 16 cases had travelled to Morocco before symptom onset, staying there between two and six weeks. In the following analysis, we describe these 15 cases. The majority (10 of 15) arrived in Morocco by car and boat through the ports of Tanger $(n=7)$, Nador $(n=1)$ or Ceuta $(n=2)$, five cases travelled by plane landing in different airports in Morocco. The period between the date of arrival in Morocco and the symptom onset was always longer than seven days (median: 20; range: $8-48$ ). We did not identify any common place (city, hotel, restaurant, supermarket) or activity shared by all cases. The food exposures most frequently mentioned were ice cream (14 of 15 cases; 14/15), grapes (10/11), chicken (13/15), pasteurised milk (13/15) and spreadable cheese (13/15). Shrimps were mentioned by five of the 15 cases. Eleven of the 15 the cases mentioned eating in a restaurant located in different cities.

In the Netherlands, 10 cases were interviewed, in Belgium, seven, in Spain, eight and in Denmark, nine. The food exposures most frequently mentioned were chicken (22 cases of 25 for which this information was available), grapes (17/20) and pasteurised milk (21/25).

Eighteen cases and 26 control-cases were interviewed, four of the 18 cases were excluded because they did not travel to Morocco $(n=2)$ or because they were considered to be secondary cases $(n=2)$. Two of the cases were matched with only one control respectively. Cases were more likely than controls to have eaten shrimps (mOR: $5.6 ; 95 \% \mathrm{Cl}: 1.1-28$ ), to have resided on the Moroccan coast (mOR: $9.3 ; 95 \% \mathrm{Cl}: 1.1-78$ ) and to have eaten shrimp in a restaurant (mOR: 11.1; $95 \% \mathrm{Cl}: 1.3-92.5)$. Cases were also more likely to have eaten in a restaurant before symptom onset (crude OR: 6.2; $95 \% \mathrm{Cl}: 1.1-295$; we could not estimate the mOR because of the small number of cases). Consumption of squid was more frequent among cases (43\%) compared with controls (15\%), but the association was not significant (Table 2).

\section{Microbiology}

The AST showed that $63 \mathrm{~S}$. Chester isolates (of 105 isolates tested, i.e. 60\%) were resistant to at least nalidixic acid with a MIC range of $24-64 \mathrm{mg} / \mathrm{L}$ (Table 3 and data not shown). Among the 39 tested strains, which were acquired in Morocco (human and non-human, 2013-2015), 35 were resistant to at least nalidixic acid. Quinolone-resistant S. Chester isolates were also found from travellers returning from the African continent (Côte d'Ivoire, $n=1$; Senegal, $n=1$ or unspecified, $n=1$ ) in 2014, from 13 French and English cases from 2014 and 2015 with no reported travel and from turkey meat imported from Spain in 2015. In silico MLST indicated that 61 of 63 quinolone-resistant isolates (including the 35 Moroccan ones) belonged to a new type, ST1954. This ST was also found in 15 quinolone-susceptible isolates (Table 3). The 61 quinolone-resistant S. Chester ST1954 isolates contained plasmid-mediated quinolone resistance (PMQR) genes. Seventeen isolates (28\%) harboured a qnrS1 gene associated with an IncN-pST7 plasmid (including the two Moroccan chicken sausage isolates) and 44 isolates (72\%) contained a qnrB19 gene associated with a Col plasmid (including the turkey meat, fishmeal and the sewage water isolates) (Table 3). Resistance to quinolones was only supported by these $q n r$ genes, as no mutation was found in quinolone-resistant determining regions ( $g y r A$, gyrB, parC and parE genes). Furthermore, a transposon belonging to the Tnz-like family was also identified and carried strA, strB, sul2, tet(A) and/or floR genes conferring resistance to streptomycin, sulfonamides, tetracycline, and/or chloramphenicol, respectively. The floR gene was only associated with the IncN-qnrS1 plasmid (Table 3).

Two main pulsed-field gel electrophoresis (PFGE) patterns, XCHE_1440 and XCHE_2010, were observed among the outbreak isolates by using the ECDC cluster detection tools (data not shown). A few other patterns were also observed among the ST1954 outbreak strains.

The WGS results showed that 153 human and nonhuman $S$. Chester isolates clustered phylogenetically into five tight groups. The grouping was concordant with MLST distribution, ST1954 $(n=96)$, ST411 $(n=23)$, 


\begin{tabular}{|c|c|c|c|c|c|c|c|c|}
\hline MLST & $\begin{array}{l}\text { Number } \\
\text { of } \\
\text { isolates }\end{array}$ & Source (n) & $\begin{array}{c}\text { Country of } \\
\text { acquisition (n) }\end{array}$ & Year (n) & AST profile $(n)$ & PFGE type & $\begin{array}{c}\text { Plasmid } \\
\text { type_pMLST }\end{array}$ & $\begin{array}{l}\text { Resistance genes } \\
\text { patterns (n) }\end{array}$ \\
\hline 343 & 14 & Human (14) & $\begin{array}{c}\text { Reported none } \\
\text { (4) } \\
\text { Unknown (4) } \\
\text { Cambodia (1) } \\
\text { India (1) } \\
\text { Indonesia (1) } \\
\text { Maldives (1) } \\
\text { Sri Lanka (1) } \\
\text { Thailand (1) }\end{array}$ & $\begin{array}{l}2012(1) \\
2013(1) \\
2014(3) \\
2015(9)\end{array}$ & $\begin{array}{l}\text { Susceptible (4) } \\
\text { Not tested (10) }\end{array}$ & $\begin{array}{c}\mathrm{XCHE} 1887 \\
(1) \\
\text { Not tested } \\
(13)\end{array}$ & $\begin{array}{c}\text { Absence (8) } \\
\text { IncFII (6) }\end{array}$ & Absence (14) \\
\hline 411 & 23 & Human (23) & $\begin{array}{c}\text { Reported none } \\
(8) \\
\text { Unknown (8) } \\
\text { Reported yes } \\
\text { (3) } \\
\text { Greece (2) } \\
\text { Burkina Faso (1) } \\
\text { Togo (1) }\end{array}$ & $\begin{array}{l}1937(1) \\
2012(2) \\
2013(1) \\
2014(13) \\
2015(6)\end{array}$ & $\begin{array}{c}\text { Susceptible (15) } \\
\text { ACroCazKGSuTmpTeNal } \\
\text { (1) } \\
\text { Not tested (7) }\end{array}$ & $\begin{array}{c}\text { XCHE_1 (1) } \\
\text { XCHE_3 (1) } \\
\text { XCHE_4 (1) } \\
\text { XCHE_1949 } \\
(1) \\
\text { Not tested } \\
\quad(19)\end{array}$ & $\begin{array}{c}\text { Absence (15) } \\
\text { Col (2) } \\
\text { incFIl (6) }\end{array}$ & $\begin{array}{c}\text { Absence (22) } \\
\text { strA, strB, sul1, dfrA18, } \\
\text { tet(D), qnrB4, bla }{ }_{\text {DHA-1 }}(1)\end{array}$ \\
\hline 1954 & 96 & $\begin{array}{c}\text { Human }(90) \\
\text { Non human } \\
\quad(6)\end{array}$ & $\begin{array}{c}\text { Reported none } \\
\text { (18) } \\
\text { Unknown (22) } \\
\text { African } \\
\text { continent (2) } \\
\text { Côte d'Ivoire (1) } \\
\text { The Gambia (1) } \\
\text { Morocco (46) } \\
\text { Netherlands (1) } \\
\text { Senegal (4) } \\
\text { Spain (1) }\end{array}$ & $\begin{array}{l}2011(1) \\
2013(4) \\
2014(59) \\
2015(32)\end{array}$ & $\begin{array}{c}\text { Susceptible (13) } \\
\text { AKNTGNal (1) } \\
\text { ASSpSuTmpCTeNal (1) } \\
\text { ASSuTmpCTeNal (2) } \\
\text { Nal (24) } \\
\text { SSuTmpCTeNal (13) } \\
\text { SuTmpCTeNal (1) } \\
\text { SuTmpNal (1) } \\
\text { SuTmpTe (2) } \\
\text { SuTmpTeNal (18) } \\
\text { Not tested (20) }\end{array}$ & $\begin{array}{c}\text { Lane4 (1) } \\
\text { XCHE_1440 } \\
(16) \\
\text { XCHE_2 (1) } \\
\text { XCHE_2010 } \\
(4) \\
\text { XCHE_2011 } \\
(1) \\
\text { XCHE_5 (1) } \\
\text { XCHE_X1 } \\
(2) \\
\text { Not tested } \\
\text { (70) } \\
\end{array}$ & \begin{tabular}{|} 
Absence (11) \\
Col (64) \\
IncN_ST7 \\
$(19)$ \\
Incl1 (6) \\
IncX1 (1)
\end{tabular} & 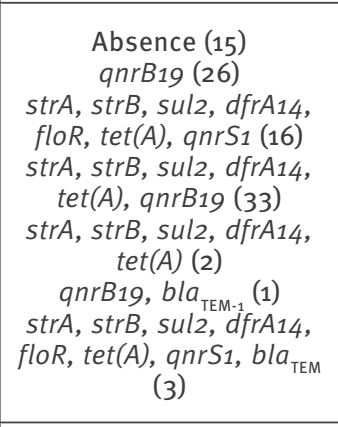 \\
\hline 1965 & 5 & Human (5) & $\begin{array}{l}\text { Reported none } \\
\text { (2) } \\
\text { Unknown (1) } \\
\text { Ghana (1) } \\
\text { Senegal (1) } \\
\end{array}$ & $\begin{array}{l}2012(1) \\
2014(1) \\
2015(3)\end{array}$ & $\begin{array}{l}\text { Susceptible (2) } \\
\text { Not tested (3) }\end{array}$ & $\begin{array}{l}\text { Not tested } \\
\text { (5) }\end{array}$ & $\begin{array}{l}\text { Absence (1) } \\
\text { IncFII (4) }\end{array}$ & Absence (5) \\
\hline 2063 & 15 & $\begin{array}{c}\text { Human (1) } \\
\text { ATCC_11997 }\end{array}$ & $\begin{array}{c}\text { Reported none } \\
\text { (2) } \\
\text { Unknown (7) } \\
\text { India (2) } \\
\text { Sri Lanka (2) } \\
\text { Thailand (1) } \\
\text { Vietnam (1) } \\
\end{array}$ & $\begin{array}{c}\text { Unknown (1) } \\
2014(6) \\
2015(8)\end{array}$ & $\begin{array}{l}\text { Susceptible (5) } \\
\text { SuTmp (1) } \\
\text { ASuTmpNal (1) } \\
\text { Not tested (8) }\end{array}$ & $\begin{array}{l}\mathrm{XCHE} \text { (1) } \\
\text { (1) }\end{array}$ & $\begin{array}{l}\text { Absence (11) } \\
\text { Incl1 (2) } \\
\text { Col (2) }\end{array}$ & $\begin{array}{c}\text { Absence (13) } \\
\text { strA, strB, sul2, dfrA14 (1) } \\
\text { strA, strB, sul2, dfrA14, } \\
\text { qnrS1, bla }{ }_{\text {TEM }}(1)\end{array}$ \\
\hline
\end{tabular}

AST: antimicrobial susceptibility testing; MLST: multilocus sequence type; PFGE: pulsed-field gel electrophoresis.

a For the country of acquisition 'reported none' indicates that the patients specified that they did not travel prior to the two weeks before their onset of symptoms, while 'unknown' indicates that no information was available as to the country of acquisition of the strain.

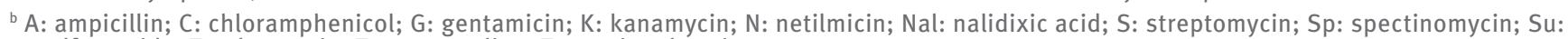
sulfonamide; T: tobramycin; Te: tetracycline; Tmp: trimethoprim.

ST2063 $(n=15), \operatorname{ST} 343(n=14)$ and ST1965 $(n=5)$ (Figure 2).

Within the ST1954 outbreak-cluster the SNP distance between strains was between 0 and 214 SNPs, the cluster itself being 8,453 SNPs distant from the reference $17 \mathrm{~K}$ genome. The epidemic ST1954 clone encompassed all S. Chester QnrS1- and QnrB19 producers of the outbreak period as well as the 15 ST1954 quinolonesusceptible strains that had been isolated since 2011. Furthermore, all the six non-human $S$. Chester isolates were distributed throughout this cluster and some of them had 5 SNP of difference with human cases (Figure 3).

\section{Discussion}

This multinational outbreak of $S$. Chester cases associated with travel to Morocco has affected at least six EU countries since 2014. The true extent of the outbreak has probably been larger than observed, with unreported cases both in visitors to and residents of the affected area. Morocco is a popular holiday destination welcoming more than 10 million international travellers in 2014. The most common countries of origin of visitors registered at the Moroccan border were France ( $n=3,494,112$ visitors) and Spain $(n=2,134,610)$ [28]. In relation to the populations of the country of residence, the highest proportions of travellers to Morocco 
in 2014 came from France $(5,405 / 100,000$ inhabitants), Belgium (5,320/100,000 inhabitants) and Spain $(4,567 / 100,000$ inhabitants). This could explain the predominance of French residents among outbreak cases. The very young age of the cases we report could be an observational bias because we caught cases who had consulted a medical doctor after their return to Europe. These cases were more likely the very young and more severely affected by salmonellosis.

In September 2014 and during the investigation, Moroccan health authorities were kept informed by ECDC and SpF and attended telephone meetings held to discuss the event. The French ministry of health informed in October 2014, through the International Health Regulation mechanism, the Moroccan ministry of health of the increase in $S$. Chester cases among French travellers returning from this country. Outbreaks of food-borne infection, only, are reportable in Morocco. No S. Chester outbreak was reported by the Moroccan authorities before and during the investigation.

The epidemiological investigations suggest that the source of the outbreak was in Morocco. We found significant associations between $S$. Chester infection and shrimp consumption, visiting the coast and restaurant attendance before symptoms. The OR associated with squid consumption was high although it did not reach statistical significance. These results suggest that seafood, shrimp in particular, could be one of the sources of this outbreak. Multiple other sources of human contamination are suggested by the molecular and WGS analysis of the non-human strains: the chicken sausage could explain the human cases with isolates carrying the incN-qnrS1 plasmid that appeared in 2014 and the turkey meat, some of human cases of 2015 with the Col-qnrB19 positive isolates. The fishmeal and the decanted water samples, also contaminated by Col-qnrB19 strains, may indicate the possible contamination of the environment by Moroccan poultries. Interestingly, fishmeal has been a major component of industrialised poultry feed [29]. Thus, to explain this contamination of different food chains, further environmental studies in Moroccan flocks are needed to highlight the potential cross-contamination/transmission mechanisms. The Col-qnrB19 and incN-qnrS1 types of plasmids have been widely described in $E$. coli and Salmonella from animals, the environment and humans worldwide [30] but IncN-pST7 plasmid has never been reported to date.

We compared the exposures of controls to the exposures of cases divided into two different groups according to the two plasmids' distribution in their $S$. Chester strains. However, this analysis did not reinforce existing associations or highlight any new association between an exposure and the $S$. Chester infection (data not shown). Only $50 \%$ of cases could be explained by self-reported consumption of shrimp. This low proportion might be due to the recall period bias or to the fact that shrimp is a stealth food vehicle used in many common dishes (salads, pizza, sauce). No association between poultry (chicken and turkey) consumption and $S$. Chester infection could be identified, probably because chicken is widely consumed by the population ( $79 \%$ of the cases and $85 \%$ of the controls in our study) and due to the low power of our study. Poultry and seafood are very commonly implicated in Salmonellarelated food-borne outbreaks [31,32]. Furthermore, seafood and chicken meat have been identified, along with beef, as products most involved in the spreading of Salmonella in Morocco [33]. Salmonella contamination of the Moroccan coast, between 2002 and 2005, has already been shown in previous studies [34,35]. Moreover, according to the RASFF database, various serotypes of Salmonella were found 27 times in fishmeal from Morocco during the period ranging from January 2010 to June 2015 (at least six S. Chester) [13].

The number of reported $S$. Chester cases in affected EU countries decreased after week 37 (mid-September) 2014 probably because most travellers came back from Morocco before the beginning of the school year. Indeed, we observed a new increase in number of S. Chester cases in September 2015 with 55 cases (at least 16 with travel history to Morocco) in France, 36 cases in Belgium, seven cases in Spain and four cases in Denmark. In 2016 in France we observed an increase again with 70 cases on the same period (between April and October), 16 had travel history to Morocco. Retrospectively, we also observed in France a slight increase in numbers of $S$. Chester cases during the summer 2013 with 14 cases during the period August-September 2013 compared with four in 2012 for the same period. The hypothesis that there are persistent sources of contamination in Morocco but also, to a lesser extent, in other West African countries is raised. In case of persistent sources and if no control measure is taken in Morocco a new increase could be observed every summers.

There were several limitations to our investigation. First, we observed that symptom onset of most of cases occurred at the end of their stay in Morocco or after they were back in France. The investigation probably missed cases who were sick during their stay and whose symptoms were already resolved before returning to France. Moreover, cases did not accurately represent all French tourists visiting Morocco, as only those seeking healthcare in France and that were tested for Salmonella were identified. Nevertheless, this should not affect the ORs, as the same limitations pertain to controls. We selected controls among other nontyphoidal Salmonella cases with other serotypes and matched them by age, travel to Morocco and exposure period. This could result in 'overmatching' and as a consequence lead to underestimating our ORs. One possible drawback of this design is that the aetiological exposures were different between serotypes, which could lead to false associations. Among our control group, nine different serotypes were included which 
would reduce this risk. The advantage of this design, in comparison with healthy people as controls, was the likely reduction of the recall bias, as ill people tend to recall different food exposures more accurately [36]. The case-case study design was already successfully used in several studies [37,38]. Unfortunately, we could not perform a multivariate analysis due to the small number of interviewed cases and controls. Finally, to our knowledge no environment and food investigations were conducted in Morocco.

The source(s) of this outbreak was located in Morocco, making it more difficult to investigate than an outbreak with a source in a EU country. However, the multinational collaboration was very helpful to share information for both the epidemiological and microbiological investigations. In this context, EPIS was very a useful tool. This kind of collaboration should be promoted and reinforced in case of outbreaks affecting several countries and occurring at a holiday destination. Specific recommendations for this outbreak were not taken because the risk posed by Salmonella in Morocco was already known and prevention and information messages already broadcasted.

In conclusion, this outbreak is probably a multi-source outbreak with several contaminated foods and likely also food chains. Chicken and shrimp in Morocco could be one of the sources of this outbreak. We recommend continuing collaboration and communication at EU level, in particular to report cases or new outbreaks through EPIS, and also to reinforce collaboration with Moroccan health authorities. Local epidemiologists could be involved in investigating such events in the field.

\section{Acknowledgements}

We are grateful to all the microbiological laboratories both in Europe and Morocco, who participate in the human Salmonella network for isolates processing.

The authors would like to thank Christiane Bouchier, Vincent Enouf and Bouchra Karraouan for their contribution in microbiological investigations, Moa Rehn for sharing the information about the Swedish case, Edith Laurent for the data entry and Marie-José Letort for her contribution in data collection in France, Catherine Ragimbeau for performing WGS of Luxembourgish strains and Pawel Stefanoff for reviewing the manuscript, the Health Inspectorate of the Flemish and French Communities for their contribution in the interview of the Belgian patients.

\section{Conflict of interest}

None declared.

\section{Authors' contributions}

LFo, NJD designed, conducted and analysed the epidemiological investigations. LM, IF, CVM, CMG and ES participated to the epidemiological study. SLH, LFa and FXW designed, conducted and analysed the microbiological investigations.
PA, JM, MT, KG, LF and TD participated to the WGS and exchanged sequences. MT, WM, SB, SHL performed PFGE and exchanged strains. $B B, A B$ and EV participated to the food traceback linked to Morocco and exchanged strains. LFo, NJD and SLH wrote the MS. All authors commented and agreed upon the final manuscript.

\section{References}

1. Gossner CM, de Jong B, Hoebe CI, Coulombier D, European Food and Waterborne Diseases Study Group. Event-based surveillance of food-and waterborne diseases in Europe: urgent inquiries (outbreak alerts) during 2008 to 2013. Euro Surveill. 2015;20(25):21166. DOI: 10.2807/1560-7917. ES2015.20.25.21166 PMID: 26132769

2. European Food Safety Authority (EFSA). European Centre for Disease Prevention and Control (ECDC), 2015. The European Union summary report on trends and sources of zoonoses, zoonotic agents and food-borne outbreaks in 2013. EFSA J. 2015;13(1):3991. Available from: http://www.efsa.europa.eu/ en/efsajournal/pub/3991

3. Majowicz SE, Musto J, Scallan E, Angulo FJ, Kirk M, O’Brien SJ, et al. , International Collaboration on Enteric Disease 'Burden of Illness' Studies. The global burden of nontyphoidal Salmonella gastroenteritis.Clin Infect Dis. 2010;50(6):882-9. DOI: $10.1086 / 650733$ PMID: 20158401

4. Grimont PAD, Weill FX. Antigenic formulae of the Salmonella serovars, 9th ed. Paris, France: WHO Collaborating Center for Reference and Research on Salmonella, Institut Pasteur; 2007. Available from: http://www.pasteur.fr/fr/sante/ centres-collaborateurs-l-oms-ccoms/salmonella

5. European Centre for Disease Prevention and control (ECDC). The Surveillance Atlas of Infectious Diseases. Stockholm: ECDC. Available from: http://ecdc.europa.eu/en/data-tools/ atlas/Pages/atlas.aspx

6. O'Grady KA, Krause V. An outbreak of salmonellosis linked to a marine turtle.Southeast Asian J Trop Med Public Health. 1999;30(2):324-7.PMID: 10774704

7. OzFoodNet Working Group. OzFoodNet: enhancing foodborne disease surveillance across Australia: quarterly report, 1 October to 31 December 2005.Commun Dis Intell Q Rep. 2006;30(1):148-53.PMID: 16637245

8. Centers for Disease Control and Prevention (CDC). Multistate outbreak of salmonella chester infections associated with frozen meals -- 18 states, 2010. MMWR Morb Mortal Wkly Rep. 2013;62(48):979-82.PMID: 24304829

9. Ries AA, Zaza S, Langkop C, Tauxe RV, Blake PA. A multistate of Salmonella Chester linked to imported Cantaloupe. Presented at 3oth Interscience conference on antimicrobial agent and chemotherapy. Atlanta. 21-24 October 1990. Washington DC: American Society for microbiology; 1990.

10. Taylor J, Galanis E, Wilcott L, Hoang L, Stone J, Ekkert J, et al. , Salmonella Chester Outbreak Investigation Team. An outbreak of salmonella chester infection in Canada: rare serotype, uncommon exposure, and unusual population demographic facilitate rapid identification of food vehicle.J Food Prot. 2012;75(4):738-42. DOI: 10.4315/0362-028X.JFP-11-408 PMID: 22488063

11. Tsuji H, Hamada K. Outbreak of salmonellosis caused by ingestion of cuttlefish chips contaminated by both Salmonella Chester and Salmonella Oranienburg.Jpn J Infect Dis. 1999;52(3):138-9.PMID: 10508002

12. Kagambèga A, Lienemann T, Aulu L, Traoré AS, Barro N, Siitonen A, et al. Prevalence and characterization of Salmonella enterica from the feces of cattle, poultry, swine and hedgehogs in Burkina Faso and their comparison to human Salmonella isolates. BMC Microbiol. 2013;13(1):253. DOI: 10.1186/1471-2180-13-253 PMID: 24215206

13. RASFF - Food and Feed Safety Alerts. Available from: https:// webgate.ec.europa.eu/rasff-window/portal/

14. Jourdan-Da Silva N, Le Hello S. Salmonelloses en France, 2002-2010: tendances en épidémiologie humaine, émergence de la souche monophasique, principaux aliments impliqués dans les dernières épidémies. [Salmonellosis in 2002-2010 in France: trends in human epidemiology, monophasic serotype emergence, main food implicated in the latest outbreaks]. Bulletin Epidémiologique Hebdomadaire Horssérie.2012;9(May):25-8. French. Available from: http://opac. invs.sante.fr/doc_num.php?explnum_id $=8148$

15. Jones G, Le Hello S, Jourdan-da Silva N, Vaillant V, de Valk $H$, Weill $F$, et al. The French human Salmonella surveillance system: evaluation of timeliness of laboratory reporting and factors associated with delays, 2007 to 2011. Euro Surveill. 
2014;19(1):20664. DOI: 10.2807/1560-7917.ES2014.19.1.20664 PMID: 24434174

16. Kelterborn E. Salmonella species. First isolations, names and occurrences. Dr. W. Junk: The Hague; 1967. pp. 109.

17. Timme RE, Pettengill JB, Allard MW, Strain E, Barrangou $\mathrm{R}$, Wehnes $\mathrm{C}$, et al. Phylogenetic diversity of the enteric pathogen Salmonella enterica subsp. enterica inferred from genome-wide reference-free SNP characters. Genome Biol Evol. 2013;5(11):2109-23. DOI: 10.1093/gbe/evt159 PMID: 24158624

18. Le Hello S, Harrois D, Bouchrif B, Sontag L, Elhani D, Guibert $\mathrm{V}$, et al. Highly drug-resistant Salmonella enterica serotype Kentucky ST198-X1: a microbiological study. Lancet Infect Dis. 2013;13(8):672-9. DOI: 10.1016/S1473-3099(13)70124-5 PMID: 23721756

19. European Committee on Antimicrobial Susceptibility Testing (EUCAST). Växjö: EUCAST. Available from: http://www.eucast. org/clinical_breakpoints/

20. Criscuolo A, Brisse S. AlienTrimmer removes adapter oligonucleotides with high sensitivity in short-insert pairedend reads. Commentary on Turner (2014) Assessment of insert sizes and adapter content in FASTQ data from NexteraXT libraries.Front Genet. 2014;5:130. DOI: 10.3389/ fgene.2014.00130 PMID: 24860597

21. Bankevich A, Nurk S, Antipov D, Gurevich AA, Dvorkin M, Kulikov AS, et al. SPAdes: a new genome assembly algorithm and its applications to single-cell sequencing. J Comput Biol. 2012;19(5):455-77. . Available from: http://www.ncbi.nlm.nih. gov/pubmed/22506599DOI: 10.1089/cmb.2012.0021 PMID: 22506599

22. Treangen TJ, Ondov BD, Koren S, Phillippy AM. The Harvest suite for rapid core-genome alignment and visualization of thousands of intraspecific microbial genomes.Genome Biol. 2014;15(11):524. DOI: 10.1186/\$13059-014-0524-X PMID: 25410596

23. Price MN, Dehal PS, Arkin AP. FastTree 2--approximately maximum-likelihood trees for large alignments.PLoS One. 2010;5(3):e9490. DOI: 10.1371/journal.pone.0009490 PMID: 20224823

24. Li H, Durbin R. Fast and accurate long-read alignment with Burrows-Wheeler transform.Bioinformatics. 2010;26(5):58995. DOI: 10.1093/bioinformatics/btp698 PMID: 20080505

25. McKenna A, Hanna M, Banks E, Sivachenko A, Cibulskis K, Kernytsky A, et al. The Genome Analysis Toolkit: a MapReduce framework for analyzing next-generation DNA sequencing data. Genome Res. 2010;20(9):1297-303. DOI: 10.1101/gr.107524.110 PMID: 20644199

26. Stamatakis A. RAxML version 8: a tool for phylogenetic analysis and post-analysis of large phylogenies.Bioinformatics. 2014;30(9):1312-3. DOI: 10.1093/bioinformatics/btu033 PMID: 24451623

27. Dallman TJ, Ashton PM, Byrne L, Perry NT, Petrovska L, Ellis R, et al. Applying phylogenomics to understand the emergence of Shiga-toxin-producing Escherichia coli $\mathrm{O}_{157}: \mathrm{H}_{7}$ strains causing severe human disease in the UK. Microbial Genomics. 2015;1(3). DOI: 10.1099/mgen.0.000029

28. Observatoire du tourisme Maroc. Statistiques sur le tourisme au Maroc pour le mois de décembre 2014. French. Available from: http://www.observatoiredutourisme.ma/wpcontent/ uploads/2015/02/TBNAT-12-14VF.pdf

29. Aviculture au Maroc. Fabrication d'aliments. [Aviculture in Morocco. Food manufacturing]. CIMAS. [Accessed 15 Feb 2017]. Available from: www.avicultureaumaroc.com/fabrication.html

30. Dolejska M, Villa L, Hasman H, Hansen L, Carattoli A. Characterization of IncN plasmids carrying bla CTX-M-1 and qnr genes in Escherichia coli and Salmonella from animals, the environment and humans.J Antimicrob Chemother. 2013;68(2):333-9. DOI: 10.1093/jac/dks387 PMID: 23060365

31. Inns T, Beasley G, Lane C, Hopps V, Peters T, Pathak K, et al. , Outbreak Control Team. Outbreak of Salmonella enterica Goldcoast infection associated with whelk consumption, England, June to October 2013. Euro Surveill. 2013;18(49):20654. .DOI: 10.2807/1560-7917. ES2013.18.49.20654 PMID: 24330940

32. Jackson BR, Griffin PM, Cole D, Walsh KA, Chai SJ. Outbreakassociated Salmonella enterica serotypes and food Commodities, United States, 1998-2008.Emerg Infect Dis. 2013;19(8):1239-44. DOI: 10.3201/eid1908.121511 PMID: 23876503

33. Bouchrif B, Paglietti B, Murgia M, Piana A, Cohen N, Ennaji $M M$, et al. Prevalence and antibiotic-resistance of Salmonella isolated from food in Morocco. J Infect Dev Ctries. 2009;3(1):3540.PMID: 19749447

34. Setti I, Rodriguez-Castro A, Pata MP, Cadarso-Suarez C, Yacoubi B, Bensmael L, et al. Characteristics and dynamics of Salmonella contamination along the coast of Agadir, Morocco.
Appl Environ Microbiol. 2009;75(24):7700-9. DOI: 10.1128/ AEM.01852-09 PMID: 19820155

35. Mannas H, Mimouni R, Chaouqy N, Hamadi F, Martinez-Urtaza J. Occurrence of Vibrio and Salmonella species in mussels (Mytilus galloprovincialis) collected along the Moroccan Atlantic coast.Springerplus. 2014;3(1):265. DOI: 10.1186/21931801-3-265 PMID: 24936389

36. McCarthy N, Giesecke J. Case-case comparisons to study causation of common infectious diseases.Int J Epidemiol. 1999;28(4):764-8. DOI: 10.1093/ije/28.4.764 PMID: 10480708

37. Krumkamp R, Reintjes R, Dirksen-Fischer M. Case-case study of a Salmonella outbreak: an epidemiologic method to analyse surveillance data.Int J Hyg Environ Health. 2008;211(1-2):163-7. DOI: 10.1016/j.ijheh.2007.02.006 PMID: 17412638

38. Bone A, Noel H, Le Hello S, Pihier N, Danan C, Raguenaud ME, et al. Nationwide outbreak of Salmonella enterica serotype 4,12:i:- infections in France, linked to dried pork sausage, March-May 2010. Euro Surveill. 2010;15(24):19592.PMID: 20576238

\section{License and copyright}

This is an open-access article distributed under the terms of the Creative Commons Attribution (CC BY 4.0) Licence. You may share and adapt the material, but must give appropriate credit to the source, provide a link to the licence, and indicate if changes were made.

This article is copyright of the authors, 2017. 